Check for updates

Cite this: RSC Adv., 2017, 7, 30542

Received 9th May 2017

Accepted 2nd June 2017

DOI: 10.1039/c7ra05243j

rsc.li/rsc-advances

\section{Chemical vapor deposition graphene combined with Pt nanoparticles applied in non-enzymatic sensing of ultralow concentrations of hydrogen peroxide}

\author{
Yawen Yuan, ${ }^{a}$ Fuhua Zhang, ${ }^{a}$ Hua Wang, ${ }^{b}$ Jinglei Liu, ${ }^{b}$ Yiqun Zheng ${ }^{b}$ \\ and Shifeng $\mathrm{Hou}(\mathbb{D} * \mathrm{~b}$
}

In this work, a glassy carbon electrode modified with Pt nanoparticles supported on chemical vapor deposition (CVD)-grown graphene (PtNPs/GR) was constructed and used to non-enzymatically detect ultralow concentrations of hydrogen peroxide. The application of in situ sputtering avoided not only the removal of surfactant from Pt nanoparticle surfaces, but also the complicated transfer of CVD-grown graphene. A PtNPs/GR free-standing film was fabricated by synergizing the good ductility of the CVDgrown graphene with the good dispersion and residual-free nature of the Pt nanoparticles. When compared with easily stacked and agglomerated powder graphene-supported Pt nanoparticles, the PtNPs/GR sensor with well-exposed active catalyst sites showed advantages in $\mathrm{H}_{2} \mathrm{O}_{2}$ detection. For example, the sensor showed a quick response of less than $3 \mathrm{~s}$, and showed a lower detection limit (0.18 $\mathrm{nM}, \mathrm{S} / \mathrm{N}=3$ ) than did similar graphene-supported Pt nanoparticle materials. In addition, the preparation method involving CVD and sputtering allows for the large-scale production of this sensor and applications in practical electrochemical detection of hydrogen peroxide.

\section{Introduction}

The ability to sensitively detect hydrogen peroxide $\left(\mathrm{H}_{2} \mathrm{O}_{2}\right)$ is essential in the environment, food and clinical fields, since $\mathrm{H}_{2} \mathrm{O}_{2}$ is an important oxidant, intermediate and by-product of some chemical reactions. Hence, effective detection of $\mathrm{H}_{2} \mathrm{O}_{2}$ is of great necessity for biological and chemical analysis. ${ }^{1,2}$ Many methods have been developed for this purpose in recent years, with these methods including chemiluminescence, ${ }^{3}$ spectrofluorimetry, ${ }^{4}$ chromatography, ${ }^{5}$ electrochemical methods, ${ }^{6}$ and so forth. Among them, electrochemical methods based on nonenzymatic detection of $\mathrm{H}_{2} \mathrm{O}_{2}$ have been widely studied due to their advantages in convenience, low cost and repeatability. ${ }^{7}$ The material components of $\mathrm{H}_{2} \mathrm{O}_{2}$ sensors have been modified to improve the electroactivity of $\mathrm{H}_{2} \mathrm{O}_{2}$ molecules with enhanced electron transfer kinetics for the purpose of obtaining multifunctional and more sensitive sensors. For example, metals and metal oxides nanoparticles, carbon nanomaterials, as well as dyes, polymers and their binary and ternary composites have been used to modify the solid electrodes of these sensors. ${ }^{8-12}$

${ }^{a}$ School of Chemistry and Chemical Engineering, Shandong University, Jinan, 250100, PR China

${ }^{b}$ National Engineering and Technology Research Center for Colloidal Materials, Shandong University, Jinan, 250100, PR China. E-mail: shifenghou@sdu.edu.cn; Fax: +86531 88363180; Tel: +8653188362815
Recently, investigations of graphene-supported noble metal nanoparticles for non-enzymatic detection of $\mathrm{H}_{2} \mathrm{O}_{2}$ were reviewed owing to the development of graphene in the electrochemical field and due to the excellent catalytic performances of noble metal nanoparticles. ${ }^{13,14}$ Graphene is an essentially twodimensional material consisting of a single layer of carbon atoms, and its resulting large specific surface area and remarkable electrical properties have resulted in its very considerable potential value in the electrochemical sensor field. ${ }^{15,16}$ In addition, the synergistic effects of graphene and noble metal nanoparticles, resulting from graphene stabilizing and supporting the noble metal nanoparticles while keeping most of their catalytic active sites exposed, have been indicated to effectively improve the electrocatalytic performances of the noble metal nanoparticles. ${ }^{17}$ Graphene-supported platinum (Pt) nanoparticle composites have attracted particular attention due to the excellent chemical stability, electroconductibility and high electrocatalytic efficiency of Pt nanoparticles. ${ }^{18-20}$

Nevertheless, graphene-supported Pt nanoparticle sensors still face some limitations. For example, processes such as mechanical exfoliation and chemical reduction methods used to prepare graphene can cause damage to the Pt nanoparticle crystals and re-stacking of the graphene layers. ${ }^{21}$ Due to the residual oxidized functional groups, the conductibility of graphene has been shown to decrease. Also, the process used to clean Pt nanoparticles is complicated since a surfactant is 
involved in their synthesis. ${ }^{22,23}$ Hence, it has been important to find a way to obtain high-quality graphene and to clean the surfaces of Pt nanoparticles in order to optimize their catalytic performance. The production of single-layer graphene using the chemical vapor deposition (CVD) method has been widely studied in the electrochemical field since this method has been shown to preserve the electronic and mechanical properties of graphene. ${ }^{24,25}$ But separating the CVD-produced graphene from the substrate and carrying out the subsequent transfer of the graphene are complicated processes, and this complication has hindered the practical use of CVD. ${ }^{26}$

In our work, we utilized a polymer-free transfer method combined with sputtering technology to obtain CVD-grown graphene in situ deposited with $\mathrm{Pt}$ nanoparticles, which were used to construct an electrochemical sensor of $\mathrm{H}_{2} \mathrm{O}_{2}$. This sensor showed enhanced electrocatalytic activity, which we attributed to various advantage of our method: the use of single-layer graphene as a platform avoided stacking and agglomeration of Pt nanoparticles and yielded a relatively high exposure of their catalytic active sites; the use of the sputtering process yielded uncontaminated Pt nanoparticle surfaces without requiring a cleaning process; and the graphene-supported Pt nanoparticle composite films were able to be free-standing after etching the growth substrate with no polymer involved to assist in the transfer. The graphene-supported Pt nanoparticle composite films were characterized, and cyclic voltammetry and amperometric curves were obtained to test the $\mathrm{H}_{2} \mathrm{O}_{2}$ detection ability of the sensor. Notably, the process of obtaining free-standing †graphene-supported Pt nanoparticle composite films without polymer-assisted transfer could find important potential use in industrial production and practical applications.

\section{Experimental}

\section{Materials and methods}

Copper $(\mathrm{Cu})$ foils with thicknesses of $25 \mu \mathrm{m}$ and $99.8 \%$ purity were bought from Alfa Aesar Company (Shanghai, China). Poly(methyl methacrylate) (PMMA, average molecular weight 97k) was purchased from Sigma-Aldrich Co. L.L.C. (Shanghai, China). Hydrogen $\left(\mathrm{H}_{2}\right)$ and methane $\left(\mathrm{CH}_{4}\right)$ gases with $99.99 \%$ purity were both purchased from Jinan Deyang Special Gas Company (Jinan, China). Reduced graphene oxide (rGO) powders were obtained from Leadernano Tech. L.L.C. (Jining, China). Hydrogen peroxide $\left(\mathrm{H}_{2} \mathrm{O}_{2}\right)$ with a $30 \%$ mass fraction, acetone $\left(\mathrm{CH}_{3} \mathrm{COCH}_{3}\right)$, acetic acid $\left(\mathrm{CH}_{3} \mathrm{COOH}\right)$, chlorobenzene $\left(\mathrm{C}_{6} \mathrm{H}_{5} \mathrm{Cl}\right)$, ammonium persulfate $\left(\left(\mathrm{NH}_{4}\right)_{2} \mathrm{~S}_{2} \mathrm{O}_{8}\right)$, disodium hydrogen phosphate dihydrate $\left(\mathrm{Na}_{2} \mathrm{HPO}_{4} \cdot 2 \mathrm{H}_{2} \mathrm{O}\right)$ and sodium dihydrogen phosphate dihydrate $\left(\mathrm{NaH}_{2} \mathrm{PO}_{4} \cdot 2 \mathrm{H}_{2} \mathrm{O}\right)$ were purchased from Sinopharm Chemical Regent Company (Shanghai, China). Aluminium oxide $\left(\mathrm{Al}_{2} \mathrm{O}_{3}\right)$ powders with

\footnotetext{
$\uparrow$ The electrodes supported with reduced graphene oxide powder and modified with Pt nanoparticles ( $\mathrm{Pt} / \mathrm{rGO} / \mathrm{GCE})$ were tested for comparison purposes and were obtained as follows: the ethanol dispersion of rGO $\left(1 \mathrm{mg} \mathrm{mL}^{-1}\right)$ was subjected to ultrasound and dropped onto the surface of a GCE $(3 \mu \mathrm{L})$; then the resulting GCE was dried and then placed into the sputtering chamber for $\mathrm{Pt}$ sputtering.
}

diameters of 500 and $300 \mathrm{~nm}$ were bought from Shanghai ChenHua Instrument Company (Shanghai, China). A phosphate-buffered solution $\left(0.1 \mathrm{~mol} \mathrm{~L}^{-1}\right)$ containing $\mathrm{NaH}_{2}$ $\mathrm{PO}_{4} \cdot 2 \mathrm{H}_{2} \mathrm{O}$ and $\mathrm{Na}_{2} \mathrm{HPO}_{4} \cdot 2 \mathrm{H}_{2} \mathrm{O}$ was used as the electrolyte. The $5 \%$ mass fraction PMMA solution was prepared by dissolving PMMA in chlorobenzene. All reagents used in the experiments were of analytical grade and used without further purification. The resistivity of the ultrapure water used was $18.2 \mathrm{M} \Omega \mathrm{cm}$.

CVD equipment was purchased from Xicheng Company (GCVD, Xiamen, China). A DESK V cold sputter unit was bought from Denton Vacuum Company (Moorestown, USA) with a platinum (Pt) target (99.999\% purity) obtained from GRIKIN Advanced Material Company (Beijing, China). A spin coater (KW4B) was bought from Institute of Microelectronics of Chinese Academy of Sciences (Beijing, China). The CHI-660C electrochemical workstation was bought from Shanghai ChenHua Instrument Company (Shanghai, China) with a standard threeelectrode system. A platinum plate electrode served as a counter electrode, a saturated calomel electrode (SCE) was used as a reference electrode, and a glassy carbon electrode (GCE) was used as a working electrode after processing. All potentials in the experiments were applied versus SCE at room temperature.

The morphologies and structures of the samples were characterized using a transmission electron microscope (TEM, JEM1011, Japan), Raman spectrometer (PHS-3C, Horbin, France) and X-ray photoelectron spectrometer (XPS, ThermoFisher K-Alpha, USA).

\section{Preparation of PtNPs/GR}

Monolayer graphene was synthesized using the low-pressure chemical vapor deposition (LPCVD) method as described in previous studies. ${ }^{27}$ First, $\mathrm{Cu}$ foils were ultrasonically cleaned using acetone and acetic acid, and dried using $\mathrm{N}_{2}$ at room temperature. Then, the cleaned $\mathrm{Cu}$ foils were loaded into a quartz tube with a diameter of $5 \mathrm{~cm}$ and heated to $1030{ }^{\circ} \mathrm{C}$ under an $\mathrm{H}_{2}$ atmosphere in a furnace. $\mathrm{CH}_{4}$ was added into the reaction chamber at the $1030{ }^{\circ} \mathrm{C}$ temperature and kept at this temperature for 30 minutes, after which the furnace was moved away and the reaction components were allowed to cool to room temperature naturally. Finally, the $\mathrm{Cu}$ foils covered with graphene were moved into the vacuum sputter device and they were immediately sputtered with Pt.

After sputtering, the samples were cut into squares with dimensions of $0.5 \mathrm{~cm} \times 0.5 \mathrm{~cm}$, and dipped into an $\left(\mathrm{NH}_{4}\right)_{2} \mathrm{~S}_{2} \mathrm{O}_{8}$ solution $\left(0.2 \mathrm{~mol} \mathrm{~L}^{-1}\right)$ to etch the $\mathrm{Cu}$ foil for six hours. After the etching process was completed, the samples were rinsed with ultrapure water several times and floated on water for temporary storage. The resulting samples were denoted as PtNPs/GR.

\section{Preparation of modified electrodes}

A bare glassy carbon electrode (GCE) was polished using a suspension containing different-sized powders of $\mathrm{Al}_{2} \mathrm{O}_{3}$, and washed with ultrapure water and ethanol to remove the adsorbed powder. Then, the GCE was dried in $\mathrm{N}_{2}$ and adhered to the PtNPs/GR floating on the water. During this process, the GCE surface was made to contact the graphene instead of the $\mathrm{Pt}$ 
nanoparticles. The modified electrode, denoted as PtNPs/GR/ GCE, was kept vertical in air to dry for about two hours, and the graphene and GCE surfaces were kept in close contact for subsequent electrochemical experiments.

The graphene-modified glassy carbon electrode (GR/GCE) was obtained by carrying out a PMMA-assisted transfer of CVD-grown graphene onto the GCE. The PMMA solution was spin-coated onto the graphene that was CVD grown on $\mathrm{Cu}$ foils $(0.5 \mathrm{~cm} \times 0.5 \mathrm{~cm})$. After curing, the sample was dipped in an $\left(\mathrm{NH}_{4}\right)_{2} \mathrm{~S}_{2} \mathrm{O}_{8}$ solution $\left(0.2 \mathrm{~mol} \mathrm{~L}^{-1}\right)$ to etch the $\mathrm{Cu}$ foils for six hours. When the etching was completed, the sample was rinsed with ultrapure water several times and the side without PMMA covered of graphene was adhered to the cleaned surface of the GCE. After the resulting sample was dried, the bare graphene on the GCE was obtained by removing PMMA with acetone. The resulting electrode was denoted as GR/GCE.

\section{Results and discussion}

\section{Principle}

The synthesis of a glassy carbon electrode modified with chemical vapor deposition (CVD)-grown graphene supporting Pt nanoparticles, denoted as PtNPs/GR/GCE, is illustrated in Scheme 1. As shown, the CVD-grown graphene on a $\mathrm{Cu}$ foil was sputtered with Pt and then etched. The resulting PtNPs/GR film can be clearly seen to be free standing on the water in the photograph. Then the modified electrode, i.e., PtNPs/GR/GCE, was constructed and tested for its ability to electrochemically detect hydrogen peroxide $\left(\mathrm{H}_{2} \mathrm{O}_{2}\right)$. The application of in situ sputtering made it unnecessary to carry out surface cleaning of Pt nanoparticles and complicated transfers of CVD-grown graphene. Furthermore, the as-prepared composites of CVD-grown graphene and Pt nanoparticles having clean surfaces can stably adhere onto the surface of an electrode using van der Waals forces. $^{28}$

\section{Characterization of PtNPs/GR}

The morphology of the PtNPs/GR film was determined by acquiring transmission electron microscopy (TEM) images, as shown in Fig. 1(A). The image showed graphene having wrinkles with micron-sized lateral dimensions, and hence able to serve as a micro-grid support, as well as Pt nanoparticles homogeneously dispersed on the graphene. The good dispersion of sputtered Pt nanoparticles on the graphene demonstrated the ability of the graphene platform to prevent the Pt nanoparticles

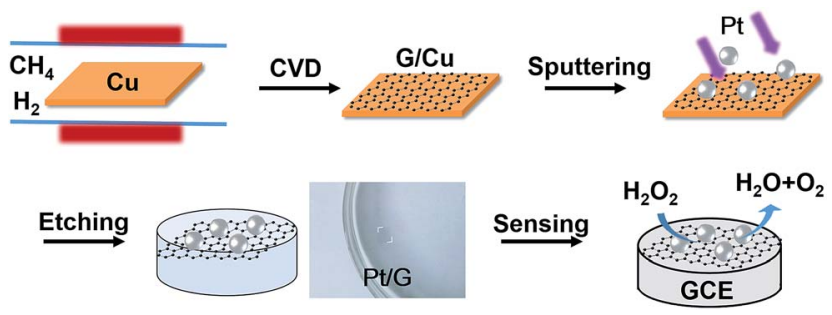

Scheme 1 Process used to synthesize PtNPs/GR/GCE.
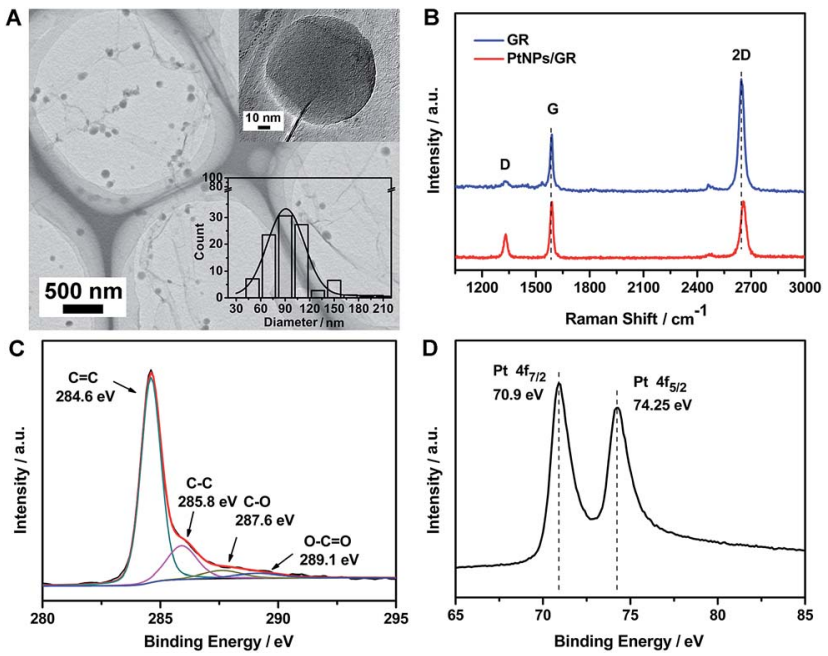

Fig. 1 (A) TEM images of PtNPs/GR. Top right inset is an HRTEM image of a single Pt nanoparticle and the bottom right inset shows the distribution of measured diameters of the Pt nanoparticles. (B) Raman spectra of graphene (blue curve) and PtNPs/GR (red curve). (C, D) XPS survey spectrum of PtNPs/GR showing the (C) C 1s and (D) Pt $4 f$ peaks.

from agglomerating and having most of their surfaces blocked. A high-resolution TEM image of a single Pt nanoparticle is shown in the top right of Fig. 1(A). This Pt nanoparticle was measured to have dimensions of about $90 \mathrm{~nm}$, which was the average size of the Pt nanoparticles (see size distribution histogram in inset in the bottom right of Fig. 1(A)).

The structure of the graphene and PtNPs/GR film were analysed by using a Raman spectrometer (Fig. 1(B)). The graphene yielded a Raman spectrum (blue curve) showing sharp $\mathrm{G}$ and 2D peaks, located at $\sim 2645.7 \mathrm{~cm}^{-1}$ and $\sim 1588.6 \mathrm{~cm}^{-1}$, respectively, indicating the good crystallinity of the graphene on the $\mathrm{Cu}$ foil. The intensity of the 2D peak revealed that the graphene was a single layer, as indicated in previous reports. ${ }^{29,30}$ The intensity of the D peak located at $\sim 1329.4 \mathrm{~cm}^{-1}$ was observed to be very low, indicating that the $\mathrm{sp}^{2}$ form of carbon was predominant in the as-prepared PtNPs/GR film. The ratio of the intensity of the 2D peak to that of the G peak was approximately unity for the composite (red curve in Fig. 1(B)), and significantly less than this ratio for the graphene; this result revealed the increased disorder in the composite. The increased disorder can be attributed to graphene rolling and forming wrinkles caused by the deposition of Pt nanoparticles during the sputtering process. In addition, the Raman spectrum of PtNPs/GR film showed a slight blue shift of the $2 \mathrm{D}$ peak and increased intensity of the D peak, which was attributed to an increased amount of defects caused during the sputtering process.

The surface chemical composition of the PtNPs/GR film was characterized using X-ray photoelectron spectroscopy (XPS). The C 1s portion of the spectrum of PtNPs/GR can be divided into four peaks, as shown in Fig. 1(C). The peaks at $284.6 \mathrm{eV}$ and $285.8 \mathrm{eV}$ corresponded to the $\mathrm{C}=\mathrm{C}$ and $\mathrm{C}-\mathrm{C}$ bonds, respectively, and those at $287.5 \mathrm{eV}$ and $289.1 \mathrm{eV}$ were indexed to $\mathrm{C}=\mathrm{O}$ and $\mathrm{O}-$ $\mathrm{C}=\mathrm{O}$. The higher energy of the $\mathrm{sp}^{2} \mathrm{C}=\mathrm{C}$ bonds suggested the formation of graphene. The formation of the oxygen-containing 
functional groups was probably caused by the oxidation of graphene during its preparation and storage, but the weak intensities of the peaks corresponding to these functional groups indicated the relative stability of graphene in the experimental conditions. As shown in Fig. 1(D), the Pt $4 \mathrm{f}$ portion of the spectrum of the PtNPs/GR film was fitted by two peaks at $70.9 \mathrm{eV}$ and $74.25 \mathrm{eV}$, which we indexed to $\mathrm{Pt}(0) 4 \mathrm{f} 7 / 2$ and $\mathrm{Pt}(0)$ 4f $5 / 2$, respectively. All of the observed binding energy values for $\mathrm{C} 1 \mathrm{~s}$ and $\mathrm{Pt} 4 \mathrm{f}$ were consistent with those reported in the literature. ${ }^{31}$ The presence of the $\mathrm{Pt} 4 \mathrm{f}$ peaks confirmed the feasibility of depositing Pt nanoparticles on the surface of graphene using the sputtering technology.

\section{Electrochemical behaviour of the PtNPs/GR-modified glassy carbon electrodes toward the sensing of $\mathrm{H}_{2} \mathrm{O}_{2}$}

The electrochemical behavior of the PtNPs/GR-modified glassy carbon electrodes (PtNPs/GR/GCE) toward the $\mathrm{H}_{2} \mathrm{O}_{2}$ oxidation reaction was analysed in a phosphate-buffered solution, as shown in Fig. 2. According to cyclic voltammogram (CV) tests at a scan rate of $0.05 \mathrm{~V} \mathrm{~s}^{-1}$ from $-0.3 \mathrm{~V}$ to $0.8 \mathrm{~V}$, the capacitance of
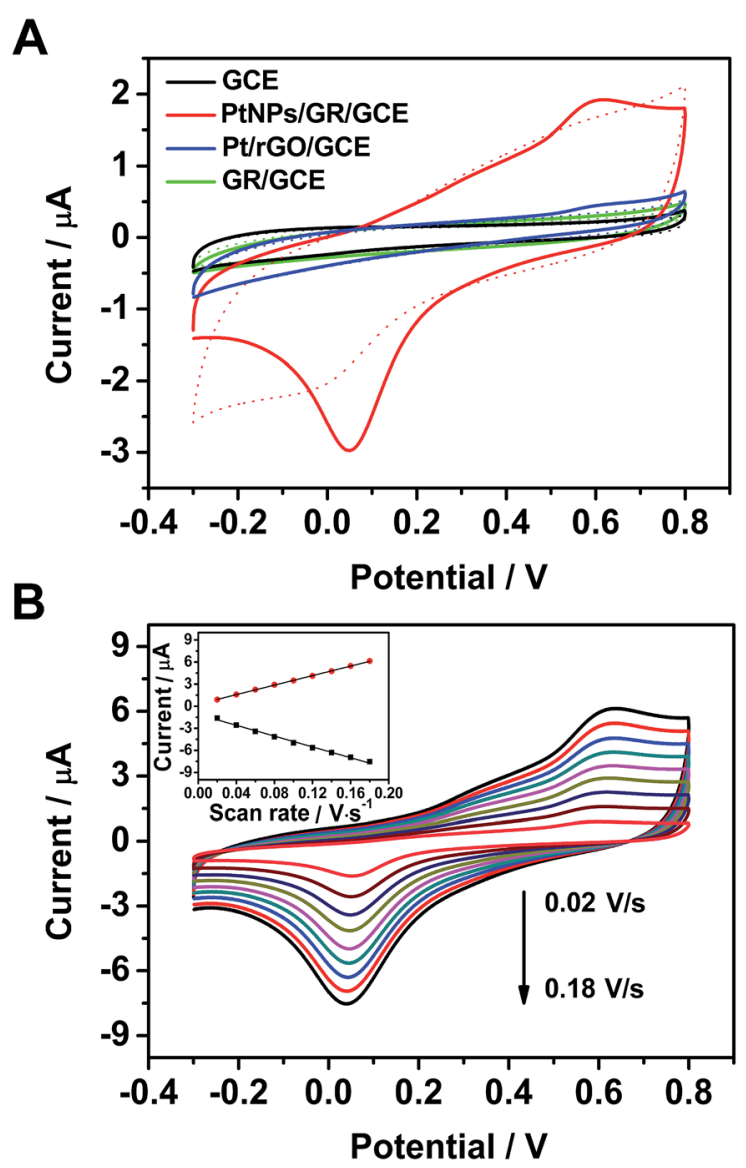

Fig. 2 (A) Cyclic voltammogram curves of GCE (black curve), PtNPs/ GR/GCE (red curve), Pt/rGO/GCE (blue curve) and GR/GCE (green curve) in a phosphate-buffered solution and in the absence (dashed line) and presence (solid line) of $5 \mu \mathrm{M} \mathrm{H}_{2} \mathrm{O}_{2}$ with a scan rate of $50 \mathrm{mV}$ $\mathrm{s}^{-1}$. (B) PtNPs/GR/GCE in a phosphate-buffered solution containing 5 $\mu \mathrm{M} \mathrm{H}_{2} \mathrm{O}_{2}$ at various scan rates with regular intervals of $20 \mathrm{mV} \mathrm{s}^{-1}$. The inset shows the plots of current versus scan rate at $0.05 \mathrm{~V}$ and $0.55 \mathrm{~V}$.
PtNPs/GR/GCE was found to be greater than those of $\mathrm{Pt} / \mathrm{rGO} /$ GCE, GR/GCE and GCE in phosphate-buffered solution without $\mathrm{H}_{2} \mathrm{O}_{2}$ (dashed line in Fig. 2(A)). When $25 \mu \mathrm{L}$ of $\mathrm{H}_{2} \mathrm{O}_{2}$ $(5 \mu \mathrm{M}$ ) was added, the GR/GCE (green solid line) and GCE (black solid line) yielded no obvious peaks in the CV curves, but PtNPs/ GR/GCE (red solid line) did yield obvious peaks at $0.05 \mathrm{~V}$ and $0.55 \mathrm{~V}$, which indicated a good response of the modified electrode to a low concentration of $\mathrm{H}_{2} \mathrm{O}_{2}$. In contrast, the current for $\mathrm{Pt} / \mathrm{rGO} / \mathrm{GCE}$ (blue solid line) showed a very small peak at $0.55 \mathrm{~V}$, which can be accounted for by the stacked layers of graphene.
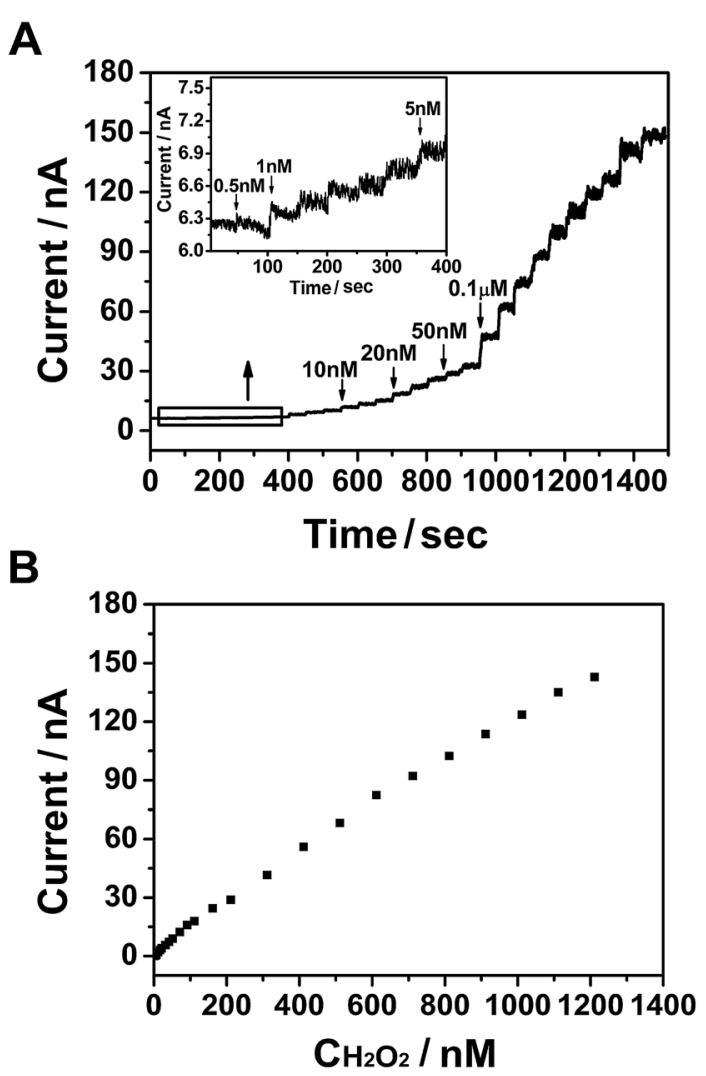

Fig. 3 (A) Amperometric curve for PtNPs/GR/GCE with the injection of $\mathrm{H}_{2} \mathrm{O}_{2}$ at $0.55 \mathrm{~V}$ with regular intervals of $50 \mathrm{~s}$. Inset shows an enlarged view of the curve from 0 to $400 \mathrm{~s}$. (B) Plot of current versus $\mathrm{H}_{2} \mathrm{O}_{2}$ concentration.

Table 1 Comparison of graphene-supported Pt nanoparticle sensors for non-enzymatic determination of $\mathrm{H}_{2} \mathrm{O}_{2}$ concentration

\begin{tabular}{llll}
\hline Materials & Linear range $(\mu \mathrm{M})$ & $\begin{array}{l}\text { Detection limit } \\
(\mu \mathrm{M})\end{array}$ & Ref. \\
\hline rGO-PtNPs & $0.05-750.6$ & 0.016 & 18 \\
PNEGHNs $^{a}$ & $1-500$ & 0.08 & 19 \\
Pt/PG $^{b}$ & $1-1477$ & 0.5 & 20 \\
$\mathrm{GN}^{\mathrm{Pt}}$ & $2-710$ & 0.5 & 33 \\
$\mathrm{Pt} / \mathrm{GN}$ & $2.5-6650$ & 0.8 & 34 \\
$\mathrm{PtNPs} / \mathrm{GR}^{c}$ & $0.0005-0.001286$ & 0.00018 & This work
\end{tabular}

${ }^{a} \mathrm{Pt}$ nanoparticle ensemble on graphene hybrid nanosheet. ${ }^{b} \mathrm{Pt}$ nanoparticle-decorated porous graphene. ${ }^{c} \mathrm{Pt}$ nanoparticles supported on CVD-grown graphene. 
Table $2 \quad \mathrm{H}_{2} \mathrm{O}_{2}$ sensing in human serum samples using PtNPs/GR/GCE $(n=3)^{a}$

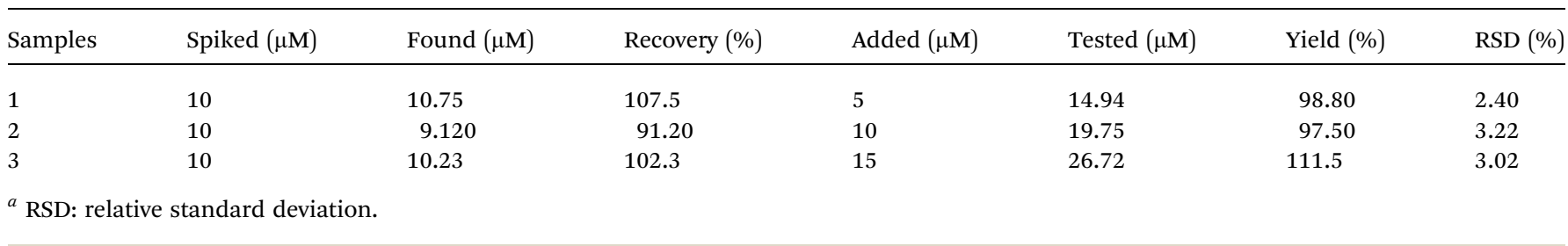

The electrochemical characteristics of PtNPs/GR/GCE containing $5 \mu \mathrm{M} \mathrm{H}_{2} \mathrm{O}_{2}$ in the phosphate-buffered solution was further investigated by acquiring $\mathrm{CV}$ curves with different scan rate. The redox peak current clearly changed as the scan rate was varied between $0.02 \mathrm{~V} \mathrm{~s}^{-1}$ to $0.18 \mathrm{~V} \mathrm{~s}^{-1}$ (in steps of $0.02 \mathrm{~V}$ $\mathrm{s}^{-1}$ ) as shown in Fig. 2(B). As shown in the inset of Fig. 2(B), the peak currents at $0.05 \mathrm{~V}$ and $0.55 \mathrm{~V}$ each showed a linear dependence on scan rate, with correlation coefficients of 0.995 and 0.999 , respectively. The fitted data implied that the dynamics control was an adsorption process.

\section{Amperometric determination of the concentration of $\mathrm{H}_{2} \mathrm{O}_{2}$}

The amperometric method was used to investigate the ability of PtNPs/GR/GCE to determine the concentration of $\mathrm{H}_{2} \mathrm{O}_{2}$ at $0.55 \mathrm{~V}$ in a phosphate-buffered solution, as shown in Fig. 3. The solution was bubbled with $\mathrm{N}_{2}$ for 30 minutes and kept stirring when $\mathrm{H}_{2} \mathrm{O}_{2}$ added. Different concentrations of $\mathrm{H}_{2} \mathrm{O}_{2}(25 \mu \mathrm{L})$ were injected into the phosphate-buffered solution every $50 \mathrm{~s}$ (Fig. 3(A)). When the concentration of $\mathrm{H}_{2} \mathrm{O}_{2}$ was increased from $0.5 \mathrm{nM}$ to $0.1 \mu \mathrm{M}$ via successive injections, the current curve showed a step-wise increase within a response time of less than $3 \mathrm{~s}$ (and reached 95\% of the maximum response value). The inset of Fig. 3(A) shows an enlarged view of the current-time curve when $0.5 \mathrm{nM} \mathrm{H}_{2} \mathrm{O}_{2}$ was injected. A current in the order of magnitude of $10^{-9} \mathrm{~A}$ was observed, and was caused by the hydrophobicity of graphene. ${ }^{32}$ The current increased when $1 \mathrm{nM}$ $\mathrm{H}_{2} \mathrm{O}_{2}$ was injected into the solution, and continued to do so as more $\mathrm{H}_{2} \mathrm{O}_{2}$ was injected. This result revealed the good electrochemical performance of the sensor, specifically its ability to respond to a low concentration of $\mathrm{H}_{2} \mathrm{O}_{2}$.

The response current value versus concentration of $\mathrm{H}_{2} \mathrm{O}_{2}$ was plotted in Fig. 3(B), and showed a good linear relationship that followed the equation $I=1.195 \times 10^{-10} \times C+3.539 \times 10^{-9}$ (nA, nM, $R^{2}=0.998$ ). The $\mathrm{H}_{2} \mathrm{O}_{2}$ sensor based on PtNPs/GR/GCE exhibited linear detection range from $0.5 \mathrm{nM}$ to $1.286 \mu \mathrm{M}$ and detection limit of $0.18 \mathrm{nM}(\mathrm{S} / \mathrm{N}=3)$, which also showed the excellent potential of this electrode to detect ultralow concentrations of $\mathrm{H}_{2} \mathrm{O}_{2}$.

The detection performances of similar materials are listed in Table 1 for comparison. PtNPs/GR/GCE showed a lower detection limit $(0.18 \mathrm{nM})$ at a signal-to-noise ratio of 3 than did the other powder graphene-supported Pt nanoparticles materials. The favourable analytical performance to detect ultralow concentrations of $\mathrm{H}_{2} \mathrm{O}_{2}$ was attributed to the good dispersion and untreated surface of the Pt nanoparticles with exposed catalytic active sites on the surface of CVD graphene. Furthermore, the lack of stacking of graphene layers in PtNPs/GR and the lack of agglomeration of Pt nanoparticles, as well as the low initial current, may have been the key factors responsible for the better ability of PtNPs/GR/GCE to detect ultralow concentrations of $\mathrm{H}_{2} \mathrm{O}_{2}$.

The standard addition method was used to detect $\mathrm{H}_{2} \mathrm{O}_{2}$ in real samples for the purpose of evaluating the practical application of PtNPs/GR/GCE. Percentage recovery was calculated as listed in Table 2 . The results showed satisfactory recovery and relative standard deviations (RSDs), illustrating the potential feasibility of the PtNPs/GR/GCE sensor to detect $\mathrm{H}_{2} \mathrm{O}_{2}$ in real samples. The sensor shows $95 \%$ of its initial current after having been stored in a desiccator at room temperature for two weeks, indicating the good stability of its electrochemical response to $\mathrm{H}_{2} \mathrm{O}_{2}$.

\section{Conclusions}

In conclusion, a composite of Pt nanoparticles on CVD-grown graphene (PtNPs/GR) was successfully prepared for the nonenzymatic detection of $\mathrm{H}_{2} \mathrm{O}_{2}$. A free-standing PtNPs/GR film was obtained by sputtering Pt on the surface of CVD-grown graphene without transfer of graphene from the growth substrate. Residual-free graphene and a Pt surface with exposed active sites, as well as the good quality of the CVD-grown graphene, contributed to the satisfactory catalytic performance of the composite toward $\mathrm{H}_{2} \mathrm{O}_{2}$. The PtNPs/GR/GCE sensor showed a low initial current (with a magnitude of $10^{-9} \mathrm{~A}$ ) and detection limit (0.18 nM, $\mathrm{S} / \mathrm{N}=3)$, and exhibited higher sensitivity at detecting ultralow concentrations of $\mathrm{H}_{2} \mathrm{O}_{2}$ than did previously reported sensors. In addition, the PtNPs/GR/GCE sensor was highly stable and showed a rapid response $(2 \mathrm{~s})$. On account of the synthesis process and enhanced catalytic performance, the PtNPs/GR composite exhibited potential applications in $\mathrm{H}_{2} \mathrm{O}_{2}$ detection, including in real samples.

\section{Acknowledgements}

This work was financially supported by the National Natural Science Foundation of China (Grant No. 21475076) and International S\&T collaboration Program of China (No. 2015DFA50060).

\section{Notes and references}

1 M. Valko, M. Izakovic, M. Mazur, C. J. Rhodes and J. Telser, Mol. Cell. Biochem., 2004, 266, 37-56.

2 S. G. Rhee, Science, 2006, 312, 1882-1883. 
3 M. Deng, S. J. Xu and F. N. Chen, Anal. Methods, 2014, 6, 3117-3123.

4 F. X. Zhan, Q. Yang, Q. F. Wang, Q. L. Zhang, Z. Y. Zhuang, X. Feng, G. Y. Zhang and G. X. Zheng, RSC Adv., 2016, 6, 89940-89943.

5 P. Ju, Y. H. Xiang, Z. B. Xiang, M. Wang, Y. Zhao, D. Zhang, J. Q. Yu and X. X. Han, RSC Adv., 2016, 6, 17483-17493.

6 L. Y. Meng, D. L. Jiang, C. S. Xing, X. M. Lu and M. Chen, RSC Adv., 2015, 5, 82496-82502.

7 W. Chen, S. Cai, Q. Q. Ren, W. Wen and Y. D. Zhao, Analyst, 2012, 137, 49-58.

8 J. Yu, X. Y. Ma, W. Y. Yin and Z. J. Gu, RSC Adv., 2016, 6, 81174-81183.

9 S. Zhang, Q. L. Sheng and J. B. Zheng, RSC Adv., 2015, 5, 26878-26885.

10 S. J. He, B. Y. Zhang, M. M. Liu and W. Chen, RSC Adv., 2014, 4, 49315-49323.

11 S. J. He, Z. G. Chen, Y. Y. Yu and L. J. Shi, RSC Adv., 2014, 4, 45185-45190.

12 X. X. Dong, M. Y. Li, N. N. Feng, Y. M. Sun, C. Yang and Z. L. Xu, RSC Adv., 2015, 5, 86485-86489.

13 R. Zhang and W. Chen, Biosens. Bioelectron., 2017, 89, 249268.

14 G. Gnana kumar, K. Justice Babu, K. S. Nahm and Y. J. Hwang, RSC Adv., 2014, 4, 7944-7951.

15 A. K. Geim and K. S. Novoselov, Nat. Mater., 2007, 6, 183-191. 16 M. Pumera, Chem. Soc. Rev., 2010, 39, 4146-4157.

17 S. Chen, R. Yuan, Y. Chai and F. Hu, Microchim. Acta, 2013, 180, 15-32.

18 S. Palanisamy, H. F. Lee, S. M. Chen and B. Thirumalraj, RSC Adv., 2015, 5, 105567-105573.

19 S. Guo, D. Wen, Y. Zhai, S. Dong and E. Wang, ACS Nano, 2010, 4, 3959-3968.

20 J. Liu, X. Bo, Z. Zhao and L. Guo, Biosens. Bioelectron., 2015, 74, 71-77.
21 S. Park and R. S. Ruoff, Nat. Nanotechnol., 2009, 4, 217-224. 22 N. V. Long, M. Ohtaki, M. Uchida, R. Jalem, H. Hirata, N. D. Chien and M. Nogami, J. Colloid Interface Sci., 2011, 359, 339-350.

23 P. Karam and L. I. Halaoui, Anal. Chem., 2008, 80, 54415448.

24 D. A. Brownson, S. A. Varey, F. Hussain, S. J. Haigh and C. E. Banks, Nanoscale, 2014, 6, 1607-1621.

25 D. A. Brownson and C. E. Banks, Phys. Chem. Chem. Phys., 2012, 14, 8264-8281.

26 X. Liang, B. A. Sperling, I. Calizo, G. Cheng, C. A. Hacker, Q. Zhang, Y. Obeng, K. Yan, H. Peng, Q. Li, X. Zhu, H. Yuan, A. R. Hight Walker, Z. Liu, L. M. Peng and C. A. Richter, ACS Nano, 2011, 5, 9144-9153.

27 X. Li, W. Cai, J. An, S. Kim, J. Nah, D. Yang, R. Piner, A. Velamakanni, I. Jung, E. Tutuc, S. K. Banerjee, L. Colombo and R. S. Ruoff, Science, 2009, 324, 1312-1314. 28 T. J. Booth, P. Blake, R. R. Nair, D. Jiang, E. W. Hill, U. Bangert, A. Bleloch, M. Gass, K. S. Novoselov, M. I. Katsnelson and A. K. Geim, Nano Lett., 2008, 8, 24422446.

29 A. C. Ferrari, J. C. Meyer, V. Scardaci, C. Casiraghi, M. Lazzeri, F. Mauri, S. Piscanec, D. Jiang, K. S. Novoselov, S. Roth and A. K. Geim, Phys. Rev. Lett., 2006, 97, 187401.

30 L. M. Malard, M. A. Pimenta, G. Dresselhaus and M. S. Dresselhaus, Phys. Rep., 2009, 473, 51-87.

31 E. Paparazzo, Carbon, 2013, 63, 578-581.

32 J. S. Park, K. D. Kihm, H. Kim, G. Lim, S. Cheon and J. S. Lee, Langmuir, 2014, 30, 8268-8275.

33 F. G. Xu, Y. J. Sun, Y. Zhang, Y. Shi, Z. W. Wen and Z. Li, Electrochem. Commun., 2011, 13, 1131-1134.

34 F. Zhang, Z. Wang, Y. Zhang, Z. Zheng, C. Wang, Y. Du and W. Ye, Int. J. Electrochem. Sci., 2012, 7, 1968-1977. 